\title{
Late pediatric ventriculoperitoneal shunt failures: a Singapore tertiary institution's experience
}

\author{
Lester Lee, MBBS, MRCS(Eng),,2 Sharon Low, PhD, FRCS(SN), ${ }^{1,2}$ David Low, MBBCh, FRCS(SN), ${ }^{1-3}$ \\ Lee Ping Ng, BNS, ${ }^{1}$ Colum Nolan, MBBCh, FRCS(SN), ${ }^{1-3}$ and \\ Wan Tew Seow, MBBS, FRACS(Neurosurgery) ${ }^{1-3}$
}

${ }^{1}$ Neurosurgical Service, KKH Women's and Children's Hospital; 2Department of Neurosurgery, National Neuroscience Institute (Singapore); and ${ }^{3}$ SingHealth Duke-NUS Neuroscience Academic Clinical Program, Singapore

OBJECTIVE The introduction of ventriculoperitoneal shunts changed the way hydrocephalus was treated. Whereas much is known about the causes of shunt failure in the first few years, there is a paucity of data in the literature regarding the cause of late shunt failures. The authors conducted a study to find out the different causes of late shunt failures in their institution.

METHODS A 10-year retrospective study of all the patients who were treated in the authors' hospital between 2006 and 2015 was conducted. Late shunt failures included those in patients who had to undergo shunt revision more than 5 years after their initial shunt insertion. The patient's notes and scans were reviewed to obtain the age and sex of the patient, the time it took for the shunt to fail, the reason for failure, and the patient's follow-up.

RESULTS Forty-six patients in the authors' institution experienced 48 late shunt failures in the last 10 years. Their ages ranged from 7 to 26 years $(12.23 \pm 4.459$ years [mean \pm SD]). The time it took for the shunts to fail was between 6 and 24 years (mean $10.25 \pm 3.77$ years). Reasons for failure resulting in shunt revision include shunt fracture in 24 patients $(50 \%)$, shunt blockage in 14 patients $(29.2 \%)$, tract fibrosis in 6 patients $(12.5 \%)$, shunt dislodgement in 2 patients $(4.2 \%)$, and shunt erosion in 2 patients (4.2\%). Postoperative follow-up for the patients ranged from 6 to 138 months (mean 45.15 \pm 33.26 months).

CONCLUSIONS Late shunt failure is caused by the effects of aging on the shunt, and the complications are different from early shunt failure. A large proportion are complications associated with shunt calcification. The authors advocate a long follow-up for pediatric patients with shunts in situ to monitor them for various causes of late shunt failure.

http://thejns.org/doi/abs/10.3171/2016.8.FOCUS16277

KEY WORDS ventriculoperitoneal shunts; shunt fracture; shunt calcification; hydrocephalus

$\mathrm{I}$ N 1951, Nulsen and Spitz revolutionized the treatment of hydrocephalus via the introduction of the valve-regulated shunt to ensure unidirectional CSF flow. ${ }^{35}$ In modern neurosurgery, the ventriculoperitoneal shunt (VPS) is still the staple modus operandi for the child with hydrocephalus. ${ }^{39,46,48}$ Despite advances in technology and precision neurosurgical techniques, VPS failure remains a considerable clinical problem globally. Various studies have shown that the VPS failure rate for shunts in a pediatric population can be as significant as $41 \%-58 \%$. 2,26,49 Common causes for VPS failure include infection, shunt catheter blockage, and as over- or underdrainage. $2,8,26,32,37,47-49$ At present, there are several publications addressing pediatric VPS failure and/or its associated complications. However, we note that the majority of such literature tends to focus on early complicationsusually where the VPS fails within 1 or 2 years postoperatively. 3,4,16,32,42 Important examples are various VPS-related infections, which are commonly caused by skin bacteria inoculation into the wound or implant. ${ }^{3,4,43}$ Less frequent complications include VPS extrusion into visceral organs,

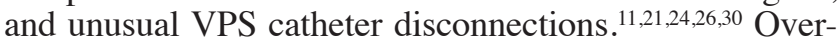

ABBREVIATIONS ETV = endoscopic third ventriculostomy; VPS = ventriculoperitoneal shunt

SUBMITTED July 1, 2016. ACCEPTED August 25, 2016.

INCLUDE WHEN CITING DOI: 10.3171/2016.8.FOCUS16277. 
all, there is a paucity of large clinical studies addressing the long-term durability and associated revision rates of VPSs in the pediatric population. One postulated observation is that long-term follow-up data in pediatric patients may be difficult to obtain. ${ }^{46}$

The neurosurgical service at KKH Women's and Children's Hospital in Singapore was started in the 1990s as a full-time subspecialty division of the pediatric surgery department. Since its humble beginnings, it has developed into a specialized neurosurgical unit dedicated to the management of pediatric neurosurgical patients. Because of its relatively recent start, it is not surprising that a common clinical issue currently faced by the unit is VPSrelated problems in a significant number of older children in whom shunts were inserted at an early age. To address this potentially life-threatening condition, we performed a retrospective study of the patients admitted for VPSrelated complications in whom the original VPS had been inserted more than 5 years before at our institution. The primary aim of the study was to analyze possible causes of VPS failure in our local pediatric population, in concordance with current literature. The secondary aims include, first, to identify factors that can be used to improve management of our present cohort of patients who have already received VPSs, especially those at risk for facing such complications. Next, the study endeavors to pinpoint possible measures that can be translated to prevent similar complications for future patients who require a VPS.

\section{Methods \\ Study Design}

This is a single-institution retrospective study approved by the hospital ethics review board. The study aims to review all VPS-related failures and follow-up shunt revisions at our institution for patients with VPSs that have been in place for more than 5 years. The study period extends over a 10-year period, from 1 January 2006 to 31 December 2015. All patients in our study were identified from our VPS hospital database; this included electronic discharge summaries, and hard-copy notes for the cases in which the electronic discharge summaries were not available.

\section{Inclusion and Exclusion Criteria}

All of our patients had a shunt that had been in place for more than 5 years at the time of hospital admission for VPS malfunction. Every shunt revision was defined as a single event. If a patient had 2 shunt revisions more than 5 years apart, then it was taken as 2 separate events. Given these parameters, a single patient could have had more than 1 shunt revision and more than 1 cause for shunt failure. This study recruited only patients whose revisions were done in our hospital. Our patients who subsequently became adults and in whom shunt revisions were done in the adult hospitals were not included in our study. Similarly, our patients in whom subsequent VPS revisions were performed in overseas hospitals were excluded in our study. Any death that occurred as a result of a VPS was also recorded in our study.

\section{Study Variables}

We recorded the patient's initial presentation, age, sex, and the initial cause of the hydrocephalus requiring a shunt insertion. Shunt fractures are related to a patient's growth, and we wanted to determine if the sudden disproportionate increase in growth during a patient's growth spurt could contribute to shunt fractures or disconnection. The time of shunt failure in relation to puberty was noted. We defined the onset of puberty as 10 years of age for girls and 11 years of age for boys. To measure VPS survival, the time to VPS revision from the initial surgery was documented. We also documented the cause of shunt failure and the follow-up period of all our patients with a VPS.

\section{Operative Methods}

Over the years, the neurosurgical service was covered by various neurosurgeons. This led to different nuances in the surgical technique for VPS insertion by individuals. However, the general procedural steps remain similar up to this day. A preoperative dose of intravenous antibiotics is given at the start of the operation. A curvilinear skin incision is made superior and posterior to the ear. This is followed by a bur hole in the skull. The ventricular tip is placed into the brain parenchyma after a small durotomy. The distal catheter is tunneled subcutaneously, down the anterior chest wall, and finally into an opening made into the peritoneum of the patient's abdominal cavity. A VPS valve is used to connect both catheters and secured in a subcutaneous pocket that is situated under the skin, usually in the postauricular region.

\section{Statistical Analysis}

Statistical analysis was conducted with Statistical Package for the Social Sciences software (SPSS, version 21.0; IBM Corp.). Logistical regression was performed to look for variables that resulted in shunt failure. A p value of $<$ 0.05 was considered statistically significant.

\section{Results}

\section{Patient Demographic Data}

A total of 315 VPSs was inserted at our institution between 1997 and 2015, according to our patient database. Of these VPSs, 132 underwent revision between 2006 and $2015 ; 48(36.4 \%)$ of these revisions were secondary to late complications, and the shunts were revised more than 5 years after the original insertion. These 48 cases occurred in 46 patients (23 males and 23 females). Two patients had more than 1 late complication each. These patients' ages ranged from 7 to 26 years (mean $12.23 \pm$ 4.459 years) (Table 1). Causes for hydrocephalus resulting in the initial shunt insertions include the following: congenital, 13 patients; postinfection, 11 patients; intraventricular hemorrhage, 9 patients; myelomeningocele, 5 patients; holoprosencephalon, 4 patients; aqueductal stenosis, 2 patients; tumor, 2 patients; encephalocele, 1 patient; and presence of intracranial cyst, 1 patient (Fig. 1). All of these patients were less than 12 months old when they had their initial VPS insertion. The postoperative follow-up for the revised shunts in our study ranged from 6 to 
TABLE 1. Demographic data, the initial cause of hydrocephalus requiring a VPS, and the late complications encountered in patients with shunt failures

\begin{tabular}{|c|c|}
\hline Factor & Value \\
\hline \multicolumn{2}{|l|}{$\operatorname{Sex}(n)$} \\
\hline Male & 23 \\
\hline Female & 23 \\
\hline Age in yrs, mean \pm SD & $7-26(12.23 \pm 4.459)$ \\
\hline \multicolumn{2}{|l|}{$\begin{array}{l}\text { Initial cause of hydrocephalus for shunt } \\
\text { insertion (n) }\end{array}$} \\
\hline Congenital hydrocephalus & 13 \\
\hline Postinfective hydrocephalus & 11 \\
\hline Intraventricular hemorrhage & 9 \\
\hline Myelomeningocele & 5 \\
\hline Holoprosencephalon & 4 \\
\hline Aqueductal stenosis & 2 \\
\hline Tumor & 2 \\
\hline Encephalocele & 1 \\
\hline Intracranial cyst & 1 \\
\hline Total no. of revisions & 48 \\
\hline \multicolumn{2}{|l|}{ Causes of late complications ( $\mathrm{n}$ ) } \\
\hline Fracture \& disconnection & 24 \\
\hline Shunt blockage & 14 \\
\hline Tract fibrosis & 6 \\
\hline Shunt tethering \& dislodgement & 2 \\
\hline Skin erosion & 2 \\
\hline Postop follow-up in mos, mean \pm SD & $6-138(45.15 \pm 33.26)$ \\
\hline Total follow-up in mos, mean \pm SD & $78-377(165.6 \pm 56.5)$ \\
\hline
\end{tabular}

138 months (mean $45.15 \pm 33.26$ months). Total follow-up for patients in our study from the time their initial shunts were inserted ranged from 78 to 377 months (mean 165.6 \pm 56.5 months). The mean is expressed \pm SD throughout.

\section{Causes of Shunt Revision}

The time it took for a shunt to fail was between 6 and 24 years (mean $10.25 \pm 3.77$ years) (Fig. 2). Reasons for failure resulting in shunt revision include the following: shunt fracture and disconnection, 24 patients (50\%); shunt blockage, 14 patients (29.2\%); tract fibrosis, 6 patients (12.5\%); shunt tethering resulting in shunt dislodgement, 2 patients (4.2\%); and skin erosion, 2 patients (4.2\%) (Fig. 3).

There were 24 patients with shunt fracture and disconnection that was found in 4 places: 2 patients had fractures that were proximal to the shunt valve, 15 patients had disconnections that were just distal to the shunt valve. The remaining 7 patients had shunt fractures at various other locations along the distal catheter, away from the valve. Puberty was not a statistically significant factor ( $\mathrm{p}$ $=0.179$ ) in shunt fractures or disconnections (Fig. 4). Six patients had catheter fractures in the neck, and 1 patient had a fractured shunt in his chest. There were 14 patients with shunt blockages: 10 shunts were blocked proximally at the ventricular catheter, whereas the other 4 had distal blockage in the peritoneal tubing. Six patients had tract fibrosis as a result of localized calcification of the shunt tubing: 4 patients had fibrosis in the neck, resulting in pain on neck movement, whereas 2 had fibrosis in the abdomen, resulting in the formation of painful intraabdominal lumps. Two shunts were dislodged because they were calcified and tethered to their surrounding tissues. Both instances required shunt revision. Two patients had skin erosion with exposed shunt tubing. One patient who had an exposed shunt in the neck had a history of cellulitis and abscess in the same region, whereas the other patient had a progressive skin erosion by the shunt catheter through his scalp simultaneously with signs of localized infection.

If shunt fractures and disconnections, tract fibrosis, and shunt tethering causing dislodgement were classified together under the spectrum of complications associated with shunt calcinosis, they would account for $66.7 \%$ of all delayed complications (32 of 48 revisions).

\section{Discussion \\ Delayed VPS Complications: an Overview}

Ventriculoperitoneal shunt placement is the mainstay of treatment for hydrocephalus secondary to a variety of underlying pathologies. ${ }^{48}$ The widespread use of VPSs has made identification and management of their associated complications all the more pertinent. In general, VPS complications can be divided into early versus late failures. Early failures are usually related to surgical technique and perioperative patient care, whereas late failures have been linked to the effects of aging on the implanted shunt material. ${ }^{5,40}$ Studies concentrating on VPS failure invariably tend to report mainly early complications due to the shorter duration of follow-up ${ }^{16}$ and/or the tendency for most VPSs to fail within 2 years of follow-up. ${ }^{3,4,26,32,42 \text {, }}$ 43,46 Therefore, comparatively speaking, there is a smaller number of studies that review definitive causes of delayed VPS complications.

Following this observation, we reviewed our local cohort of patients who underwent shunt revision after 5 years because of the increment of older children who, after several years, present with symptomatic VPS complications. This corroborates the literature that, first of all, reports that the majority of VPS catheter degradations have been found to occur after 5 years from the time of surgery. ${ }^{17,19}$ Second, early complications related to operative technique and initial patient management would be resolved after such a long time interval. Our study cohort demonstrates that the majority of patients have a VPS fracture with or without in vivo catheter disconnection, followed by VPS blockage, as the main clinical presentations for late VPS complications.

\section{Fractures and Disconnections}

Broadly speaking, the incidence of VPS fracture appears to be a late complication in the pediatric population. ${ }^{12,34}$ Most VPS fractures occur in the neck, $, 3,25,29$ and repeated motion has been postulated to be the most important factor in these fractures. ${ }^{1}$ In the cervical spine region, there is a transition from the mobile neck, which is associated with numerous turning movements in the context of an immobile chest wall. This results in increased localized 


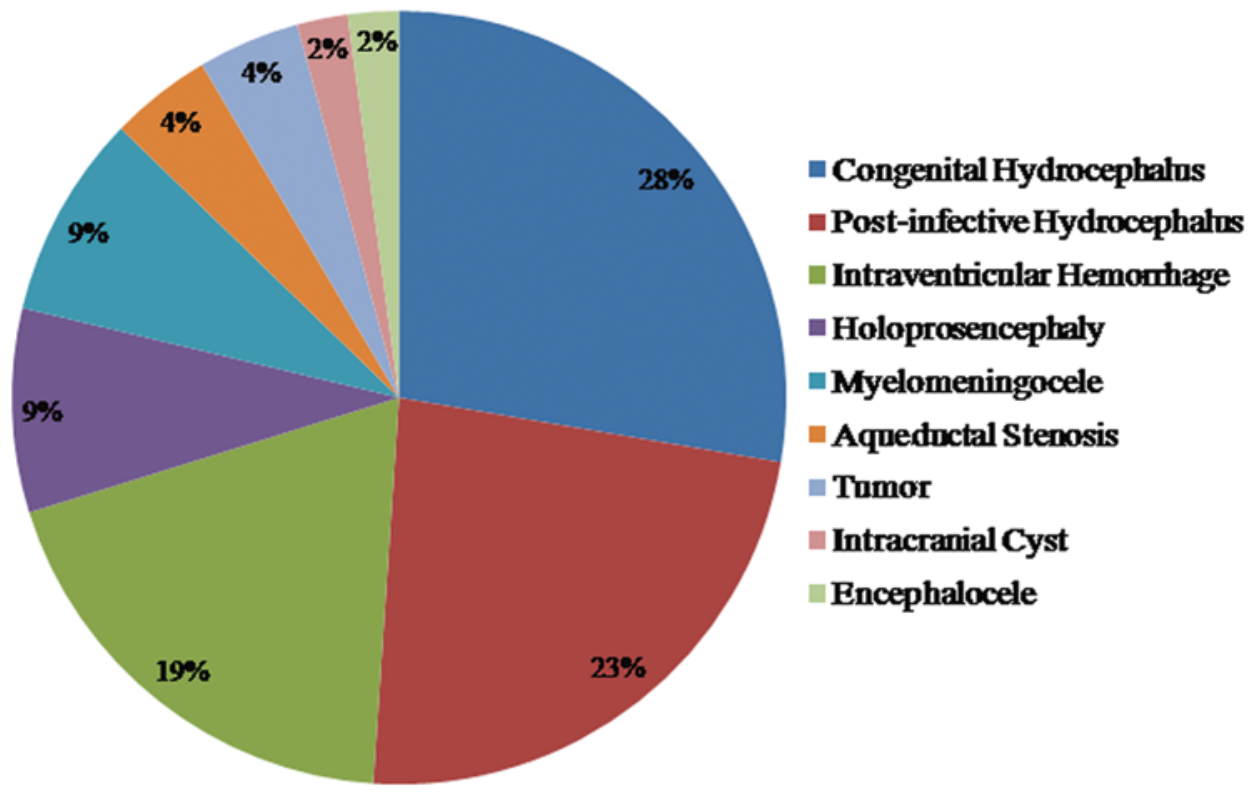

FIG. 1. Pie chart showing causes of hydrocephalus requiring a VPS.

stress on the shunt tubing in the area. Another significant point is that the continued growth of a child can result in chronic stretching of the tube, especially if it is tethered by fibrosis. Given this latter observation, coupled with the stress on the VPS tubing caused by neck movements, there is thus an increased risk of VPS fracture and/or disconnection occurring. . $^{128}$

Despite a disproportional increase in the patients' height during the adolescent growth spurt, our study does not show that the onset of puberty is a statistically significant contributory factor for VPS fracture. We theorize that the main causative factor is a temporal stretching of the VPS tubing as the child grows, which causes more biodegradation of the VPS material in the long term. This reason, in combination with an event of increased stretching

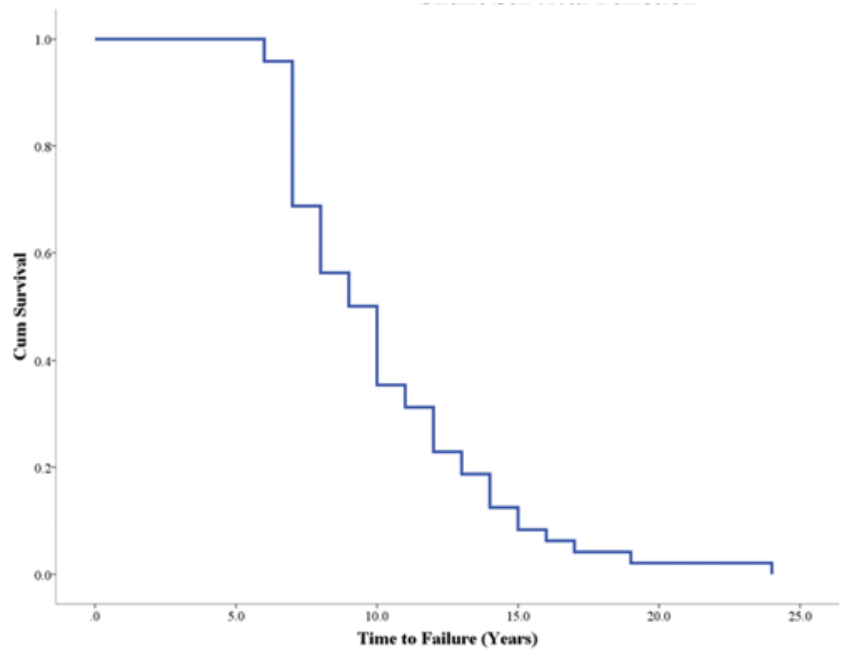

FIG. 2. Kaplan-Meier curve showing shunt survival over time. Cum = cumulative. during the adolescent growth spurt, may be the key to our patients' age at presentation.

In addition, VPS systems involving the use of connectors have been associated with a higher likelihood of VPS disconnections compared with unishunt systems. ${ }^{40}$ Sites of connections are the weakest biomechanical aspects of the VPS. Hence, they are at risk for disconnection when the catheter is tethered downward. Hence, in concordance with this known phenomenon, it is not surprising that a noteworthy number of patients in our study tend to have VPS disconnections just distal to the valve.

\section{Calcification and Related Consequences}

Ventriculoperitoneal shunt fractures and disconnections have been found to be frequently associated with calcification along the course of the implant. This phenomenon of calcified material along the VPS tubing and its influential effect on subsequent VPS fracture and/or disconnection is unique to the pediatric population with long-term VPSs. ${ }^{17,45}$ The deposition of calcium is invariably related to the younger age of the patient and the degradation of the VPS tubing. ${ }^{19}$ Furthermore, aging and biodegradation of the VPS appears to be heavily involved in the mineralization and deposition of calcium. The calcified areas are typically associated with fibrosis, causing the VPS catheter to be tethered (Fig. 5). This tethered portion of the shunt is often very stuck down and is challenging to remove during VPS revision surgery. ${ }^{10}$

Detailed physical, chemical, and mechanical studies showed that calcification was only observed on the external surface of the tubing and predominately in the subcutaneous layer of the neck and the anterior chest wall. Findings such as fragmentation of shunt polymer, presence of microfractures, and degradation of the silicone rubber causing brittleness suggest that the shunts were degraded. ${ }^{5}$ Common sites of calcification include occipital sites, lateral cervical regions, and the chest wall. This has led some 


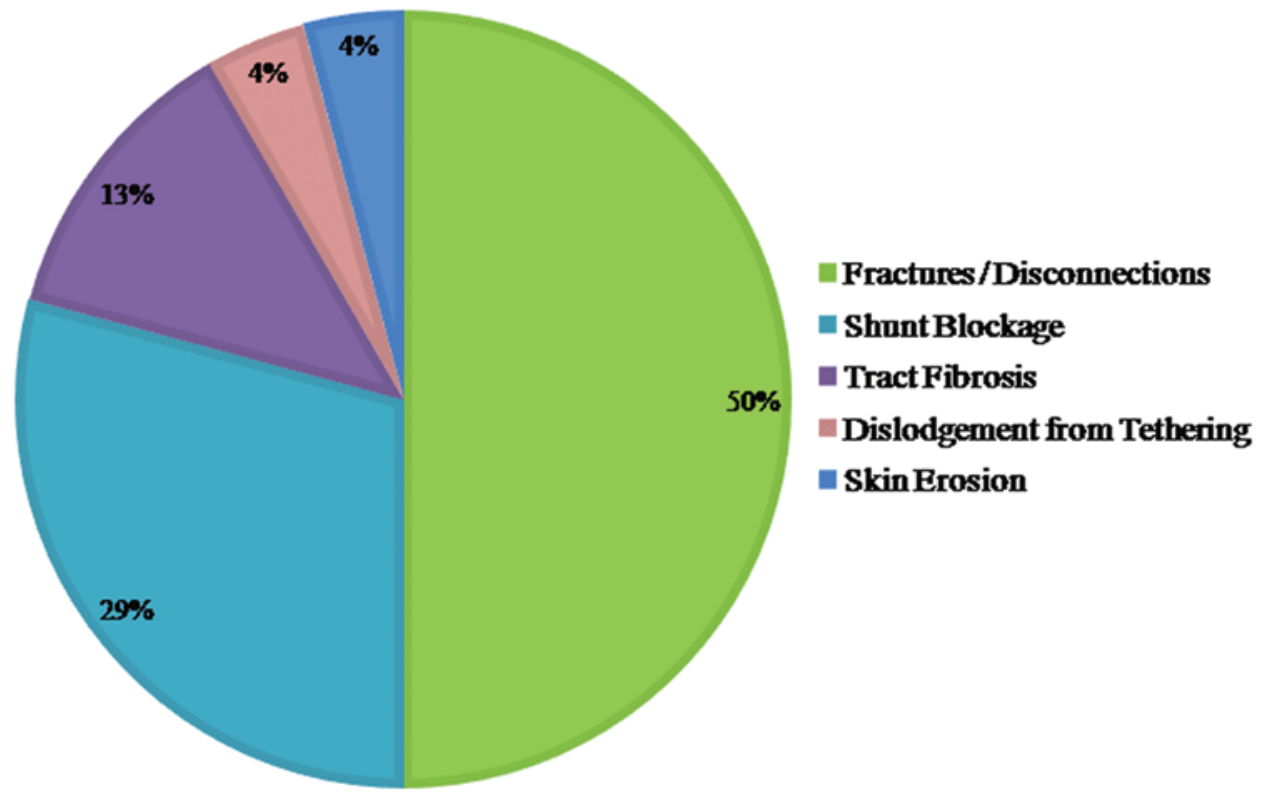

FIG. 3. Pie chart showing late shunt complications. Note that fractures and disconnections made up the majority of cases, and when tract fibrosis and dislodgment from tethering were added to fracture/disconnections because of a common pathology related to shunt calcification, these made up $67 \%$ of complications.

authors to speculate that tensile stresses that can occur on the tubing as it passes from the mobile neck to the relatively immobile chest wall are responsible for stress-related degeneration and calcium deposition. ${ }^{17,19,45}$

Various theories have been postulated to account for the mechanism of calcium formation. The first phase of calcification is the formation of a small nucleus of precipitate, after which calcium deposits grow. Formulation of calcium nuclei can occur from cellular debris that accumulate in proximity to the implant and worsen by physical deterioration of the surface conditions of the shunt, which could cause dystrophic calcium deposition. ${ }^{5}$ Chronic inflammation in the subcutaneous tissues has also been implicated in the biodegradation of the catheters. ${ }^{38}$ The presence of barium in shunts that calcify and fracture suggests that barium has a role in the calcification of these devices. ${ }^{37,38,}$ ${ }^{41,50}$ Barium particles can act as a solid interface to enhance nucleation rates, in addition to cellular debris or inflamma-

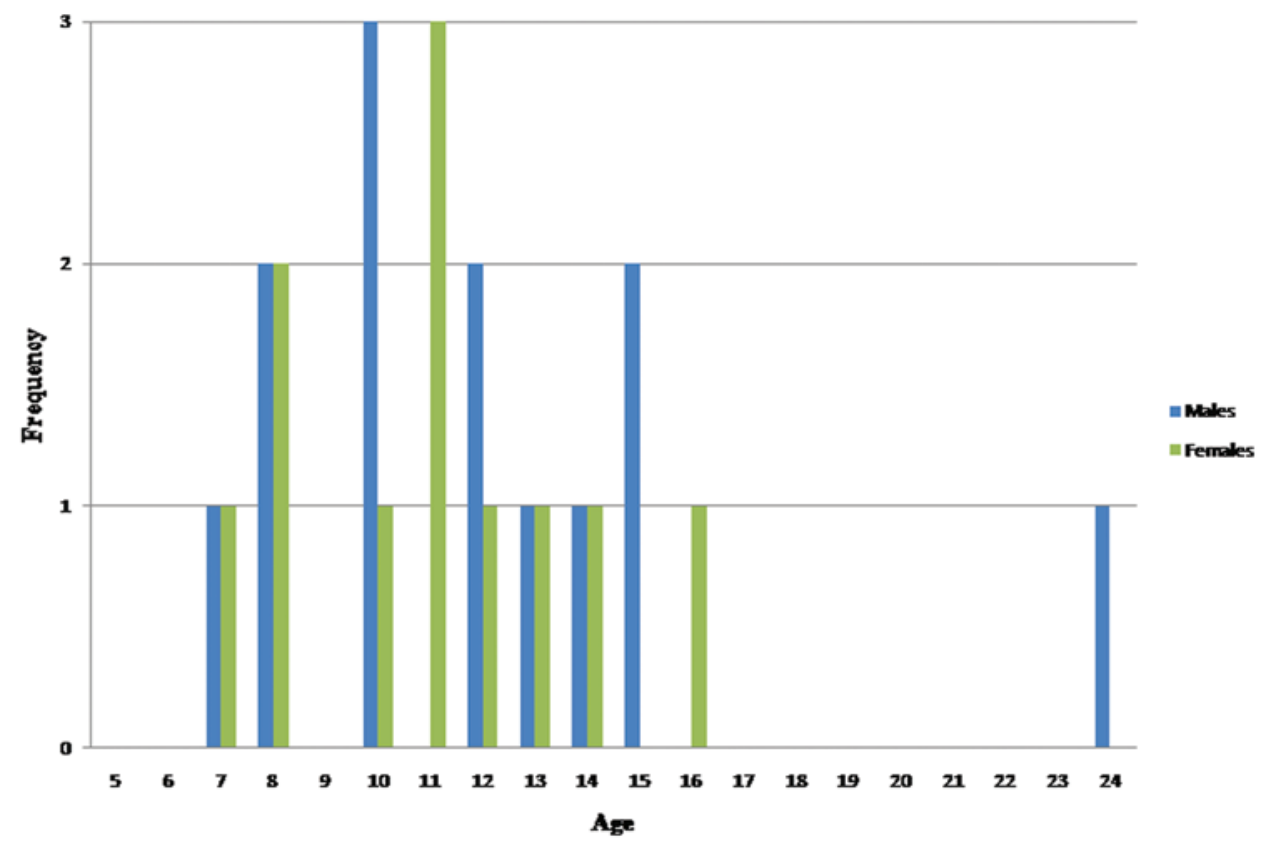

FIG. 4. Bar graph showing age of patients when shunt fractures and disconnections occurred. Despite the majority of shunts being fractured and disconnected between the ages of 10 and 16 years, puberty and the growth spurt was not a significant factor $(p=$ 0.179). 

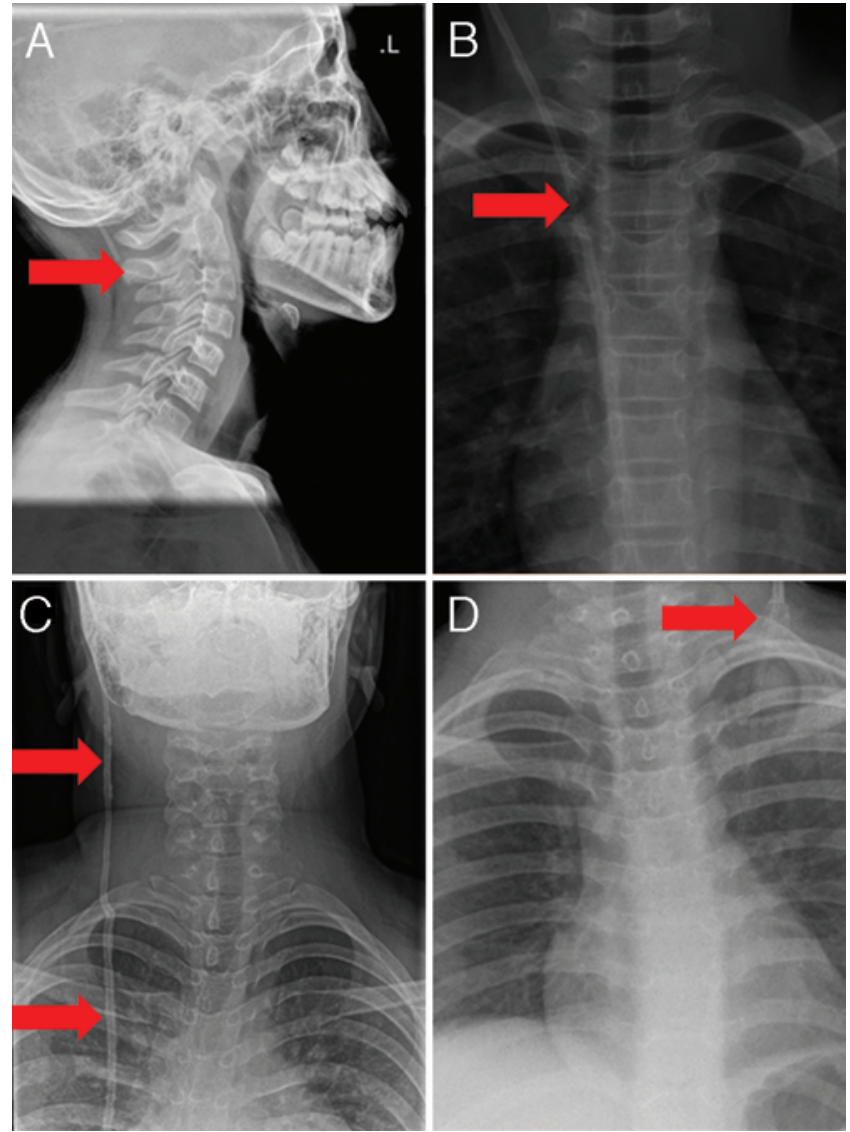

FIG. 5. A: Lateral cervical spine radiograph showing shunt fractured at the C-2 level (arrow). Distal tubing has retracted downward. B: Chest radiograph showing shunt fractured at the level of the clavicle (arrow). C: Anteroposterior cervical spine radiograph showing extensive diffuse calcifications on the shunt tubing at the level of the neck (arrow) and the chest wall (arrow). D: Chest radiograph showing a lump of calcification at the level of the neck (arrow).

tory cells on the catheters. They may also make numerous cracks, which can accelerate the degradation of the catheters. ${ }^{50}$ The risk of VPS fracture and disconnection has prompted some authors to suggest that routine revision of the VPS tubing might be beneficial in even asymptomatic calcified shunts. ${ }^{5,17}$

\section{Tethering and Tract Fibrosis}

Most publications on VPS calcification are related to shunt fractures and/or disconnections. . $10,13,25,28,29,37,38,40,41,50$ In our study, we identified other problems associated with shunt calcification. These include fibrosis and tethering to the skin, causing localized discomfort to the patients (Fig. 6). Overall, VPS catheter tethering with or without the presence of tract fibrosis is seldom discussed in the literature. In this study, we use the term "tract fibrosis" for the findings of inflammatory tissue that result from scarring and/ or calcinosis surrounding the VPS catheter. These fibrotic tissues usually take a tubular shape, mirroring that of the catheter's tube structure-hence the term tract fibrosis. In 3 of our patients presenting with VPS tethering, a palpable neck swelling was present in 1 case. This was found to be due to kinking of the catheter at the level of the first rib,
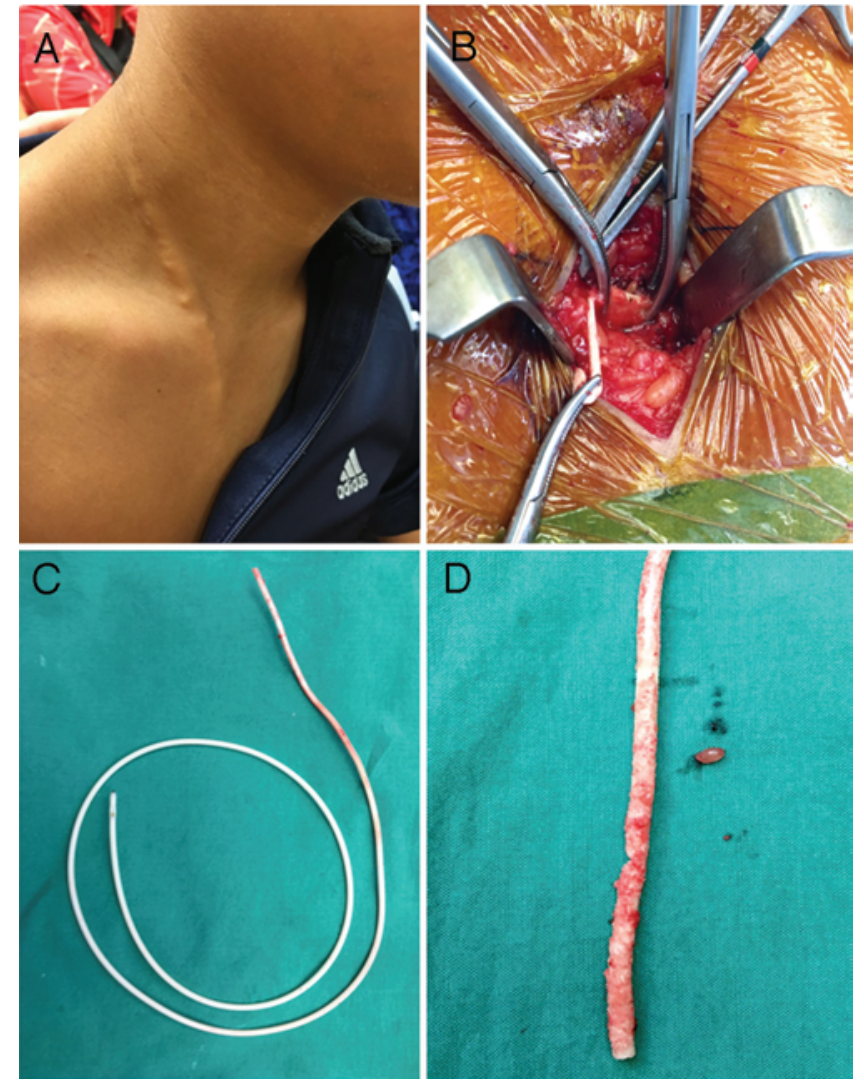

FIG. 6. A: Photograph of a patient with a calcified shunt tethered to the skin over his neck. B: Intraoperative photograph showing isolation and removal of the shunt tubing. C: Shunt tubing after removal-surgeons were usually not able to remove the whole length of tubing intact, and parts of it were tethered to the surrounding tissue and broke off. D: Close-up photograph of calcified shunt tubing.

identified on radiographs. The other 2 patients presented with neck pain that interfered with daily activities.

Our intraoperative findings revealed extensive fibrosis, calcification, and adhesions, mainly in the neck and thoracic regions. Distal revision of the VPS catheter relieved these symptoms in 2 of 3 cases. In the remaining case, the shunt catheter was removed, and symptoms resolved spontaneously. One case report describes the development of torticollis in a 14-year-old boy approximately 12 years after VPS insertion. A fibrous band tightly overlying the VPS catheter in the neck was discovered during surgery. When this was excised, the patient's symptoms were relieved. ${ }^{44}$ Previous publications have highlighted calcification as the main factor in degradation of shunt tubing. ${ }^{5,10,45,50}$ However, there are studies reporting that a proportion of VPS catheters have been found to be encircled by both calcification and fibrosis, making them adherent to surrounding structures. ${ }^{5,29}$ Hence, it is plausible that such fibrotic adherence of the VPS catheter to surrounding tissues may inhibit movement and, over time, induce further tension in nearby muscles and soft tissues, causing a repetitive triad of pain, inflammation, and swelling.

In our study, the similar intraoperative findings in patients with VPS fractures and VPS tethering suggest that the underlying pathogenesis of both conditions may have 
commonalities. We believe that they are both related to a common pathology-calcification of the VPS catheter. This process leads to tethering, synergistically with surrounding tissue fibrosis. Previous studies did not fully address this issue. Possible reasons could be that, first, their series may have been too small; and second, there was a strong focus on a singular relationship between VPS calcification and VPS fractures. It is important to recognize the complications that can result from shunt calcification because they will affect the management of the devices in these patients.

\section{Blockage and VPS-Related Skin Erosion}

In contrast to early VPS blockage, which accounts for the largest proportion of early VPS failures, 2,16,32,48 late VPS failures secondary to obstruction are not well reported. Because of its long construct, a VPS may be blocked in various regions by different ways. For instance, the proximal catheter can be obstructed by debris, blood clot, choroid plexus, or brain tissue. This has been demonstrated in both in vivo and in vitro studies. ${ }^{15}$ Alternatively, the distal catheter may be blocked by a close-spaced fluid loculation in the abdominal cavity, or the catheter tip may be encased by a fibrous sheath. An active inflammatory process related to a hypersensitivity reaction has been postulated to be responsible for such sequelae, resulting in noninfectious tissue-mediated obstruction of the distal catheter. ${ }^{17}$ In our study, most of the VPS blockage cases occurred in the proximal catheters (10 of 14), with the only discernible offender being debris obstructing the catheter lumen. However, we note that for this study, no microscopic investigations were performed on the material that was found during VPS revision surgery. Perhaps a detailed examination of such findings as the subject of future work will be able to yield meaningful information for better understanding of this condition.

Erosion of shunt parts through the skin or body surface is an uncommon complication in VPSs, and the incidence of such events is confined to just case reports.,31 Skin erosions are believed to be caused by damage to the integrity of the overlying skin, either through infection or necrosis. ${ }^{7,33,35}$ Both patients in our series with VPS catheter erosion had overlying skin infections-one had a history of neck abscess and cellulitis, whereas the other had erythematous skin with small pus pockets around the exposed VPS tubing. We believe that the VPS implant under the skin may have caused a long-term irritative process to the inner dermis, leading to repeated pressure and inflammation, and eventual erosion through the skin. This process is probably parallel to previously reported cases in which the distal VPS catheter tip eroded through the bowel via chronic irritation of the intestinal serosal surface. ${ }^{31}$

\section{Future Directions}

Mechanical dysfunction of VPSs is an important problem and a frequent cause of readmission in pediatric neurosurgery. ${ }^{6}$ In accordance with published evidence, our study demonstrates that late VPS failure is associated with the effects of aging on the VPS materials in vivo. Ventriculoperiotoneal shunt calcification is a leading cause for a large proportion of delayed VPS failures. Such compli- cations associated with calcified shunts should be regarded as a constellation of events that arise from a common pathology. Other less frequent complications in our series include VPS blockage and VPS implant erosion through the skin.

In view of our findings, we advocate the long-term monitoring of shunt-treated patients in the form of regular outpatient follow-up, with consideration of closer monitoring during their expected years of growth spurts. Particular attention should be paid during the period of adolescence, when these discussed late VPS complications are more likely to occur. Surveillance can be arranged such that it is more frequent around the time of adolescent growth; for example, a follow up could be scheduled every 6 months between the ages of 10 and 16 years. Furthermore, neck pain in patients treated with shunts should not be dismissed without thorough clinical examination and, when appropriate, the inclusion of radiological investigation. This is contingent on parental cooperation, and the importance of this follow-up must be emphasized during the initial consultation. In addition, we push for public health education to increase community awareness of clinical hydrocephalic presentation. This is paramount, especially for parents and teachers of children with a VPS; in these children a close eye is needed to be mindful of sometimes insidious symptoms of raised intracranial pressure. Such measures can potentially help reduce the time lapse between fracture and a late clinical presentation.

Nowadays, the discussion of pediatric hydrocephalus is incomplete without the mention of endoscopic third ventriculostomy (ETV). This is because there is a shift toward alternative methods that aim for the affected child to be less shunt dependent..$^{9,20,22}$ Retrospective analysis has shown that ETV for obstructive hydrocephalus has the benefit of a higher success rate, with fewer reoperations compared with VPS insertion. ${ }^{9,14,20}$ However, there remains a lack of prospective large-scale randomized studies comparing the efficacy of both methods. Besides that, some limitations of ETV are clinically relevant: these include lower suc-

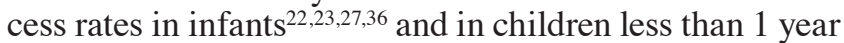
old. ${ }^{14,22,23,27,36}$ This is thought to be due to a combination of ventriculostomy closure, due to the higher capacity of infants for arachnoid proliferation, as well as immature CSF absorption capacity. Furthermore, some studies report that significant experience is required to obtain good results, and centralization of these procedures may be beneficial. ${ }^{18}$ Despite the increasing use of ETV at our institution, for the majority of patients the VPS is still the standard of care for a child with hydrocephalus. Hence, it remains valuable to continue to optimize management in existing and future patients with VPSs, and at the same time to pursue techniques that can possibly avoid VPS dependence in young children.

\section{Conclusions}

This study highlights the factors that affect durability of VPSs in pediatric patients, particularly in our local setting. More research is needed to look into such factors for affected patients. In the meantime, we advocate the ongoing optimization of the treatment of patients with late VPS complications via the development of strategies for 
lifelong follow-up, the design of a workflow protocol for medical staff to recognize and manage such patients when admitted, and focused public health education for parents and school teachers in contact with patients with a VPS. Ultimately, this is important for better patient care, especially in the context of a possibly fatal condition if prompt treatment is not instituted.

\section{References}

1. Aldrich EF, Harmann P: Disconnection as a cause of ventriculoperitoneal shunt malfunction in multicomponent shunt systems. Pediatr Neurosurg 16:309-312, 1990-1991

2. Appelgren T, Zetterstrand S, Elfversson J, Nilsson D: Longterm outcome after treatment of hydrocephalus in children. Pediatr Neurosurg 46:221-226, 2010

3. Baird C, O'Connor D, Pittman T: Late shunt infections. Pediatr Neurosurg 31:269-273, 1999

4. Bakhsh A: CSF shunt complications in infants-an experience from Pakistan. Pediatr Neurosurg 47:93-98, 2011

5. Boch AL, Hermelin E, Sainte-Rose C, Sgouros S: Mechanical dysfunction of ventriculoperitoneal shunts caused by calcification of the silicone rubber catheter. J Neurosurg 88:975-982, 1998

6. Bondurant CP, Jimenez DF: Epidemiology of cerebrospinal fluid shunting. Pediatr Neurosurg 23:254-259, 1995

7. Borkar SA, Satyarthee GD, Khan RN, Sharma BS, Mahapatra AK: Spontaneous extrusion of migrated ventriculoperitoneal shunt catheter through chest wall: a case report. Turk Neurosurg 18:95-98, 2008

8. Braga MH, Carvalho GT, Brandão RA, Lima FB, Costa BS: Early shunt complications in 46 children with hydrocephalus. Arq Neuropsiquiatr 67 (2A):273-277, 2009

9. Brockmeyer D, Abtin K, Carey L, Walker ML: Endoscopic third ventriculostomy: an outcome analysis. Pediatr Neurosurg 28:236-240, 1998

10. Cakir E, Kuzeyli K, Usul H, Peksoylu B, Karaarslan G, Yildiz K: Shunt dysfunction due to calcification of a ventriculo-peritoneal shunt: a case report. J Clin Neurosci 11:210_ 211, 2004

11. Choudhury AR: Avoidable factors that contribute to the complications of ventriculoperitoneal shunt in childhood hydrocephalus. Childs Nerv Syst 6:346-349, 1990

12. Clyde BL, Albright AL: Evidence for a patent fibrous tract in fractured, outgrown, or disconnected ventriculoperitoneal shunts. Pediatr Neurosurg 23:20-25, 1995

13. Cuka GM, Hellbusch LC: Fractures of the peritoneal catheter of cerebrospinal fluid shunts. Pediatr Neurosurg 22:101103,1995

14. de Ribaupierre S, Rilliet B, Vernet O, Regli L, Villemure JG: Third ventriculostomy vs ventriculoperitoneal shunt in pediatric obstructive hydrocephalus: results from a Swiss series and literature review. Childs Nerv Syst 23:527-533, 2007

15. Del Bigio MR, Fedoroff S: Short-term response of brain tissue to cerebrospinal fluid shunts in vivo and in vitro. J Biomed Mater Res 26:979-987, 1992

16. Drake JM, Kestle JR, Milner R, Cinalli G, Boop F, Piatt J Jr, et al: Randomized trial of cerebrospinal fluid shunt valve design in pediatric hydrocephalus. Neurosurgery 43:294-305, 1998

17. Echizenya K, Satoh M, Murai H, Ueno H, Abe H, Komai T: Mineralization and biodegradation of CSF shunting systems. J Neurosurg 67:584-591, 1987

18. Egger D, Balmer B, Altermatt S, Meuli M: Third ventriculostomy in a single pediatric surgical unit. Childs Nerv Syst 26:93-99, 2010

19. Elisevich K, Mattar AG, Cheeseman F: Biodegradation of distal shunt catheters. Pediatr Neurosurg 21:71-76, 1994
20. Gangemi M, Donati P, Maiuri F, Longatti P, Godano U, Mascari C: Endoscopic third ventriculostomy for hydrocephalus. Minim Invasive Neurosurg 42:128-132, 1999

21. Greene C Jr, Valerie E: Retroperitoneal, paraspinal migration of distal ventriculoperitoneal shunt catheter: a peculiar complication of cerebrospinal fluid shunt. Pediatr Neurosurg 49:86-88, 2013

22. Hellwig D, Grotenhuis JA, Tirakotai W, Riegel T, Schulte DM, Bauer BL, et al: Endoscopic third ventriculostomy for obstructive hydrocephalus. Neurosurg Rev 28:1-38, 2005

23. Jernigan SC, Berry JG, Graham DA, Goumnerova L: The comparative effectiveness of ventricular shunt placement versus endoscopic third ventriculostomy for initial treatment of hydrocephalus in infants. J Neurosurg Pediatr 13:295-300, 2014

24. Kanojia R, Sinha SK, Rawat J, Wakhlu A, Kureel S, Tandon $\mathrm{R}$ : Unusual ventriculoperitoneal shunt extrusion: experience with 5 cases and review of the literature. Pediatr Neurosurg 44:49-51, 2008

25. Kaplan M, Cakin H, Ozdemir N, Gocmez C, Ozturk S, Erol FS: Is the elapsed time following the placement of a ventriculoperitoneal shunt catheter an individual risk factor for shunt fractures? Pediatr Neurosurg 48:348-351, 2012

26. Khan F, Shamim MS, Rehman A, Bari ME: Analysis of factors affecting ventriculoperitoneal shunt survival in pediatric patients. Childs Nerv Syst 29:791-802, 2013

27. Kulkarni AV, Drake JM, Mallucci CL, Sgouros S, Roth J, Constantini S, et al: Endoscopic third ventriculostomy in the treatment of childhood hydrocephalus. J Pediatr 155:254259, 259.e1, 2009

28. Kural C, Kirik A, Pusat S, Senturk T, Izci Y: Late calcification and rupture: a rare complication of ventriculoperitoneal shunting. Turk Neurosurg 22:779-782, 2012

29. Lee YH, Park EK, Kim DS, Choi JU, Shim KW: What should we do with a discontinued shunt? Childs Nerv Syst 26:791-796, 2010

30. Lo WB, Ramirez R, Rodrigues D, Solanki GA: Ventriculoperitoneal shunt disconnection associated with spontaneous knot formation in the peritoneal catheter. BMJ Case Rep 2013: bcr2013009590, 2013

31. Low SW, Sein L, Yeo TT, Chou N: Migration of the abdominal catheter of a ventriculoperitoneal shunt into the mouth: a rare presentation. Malays J Med Sci 17:64-67, 2010

32. Miranda P, Simal JA, Menor F, Plaza E, Conde R, Botella C: Initial proximal obstruction of ventriculoperitoneal shunt in patients with preterm-related posthaemorrhagic hydrocephalus. Pediatr Neurosurg 47:88-92, 2011

33. Monas J, Peak DA: Spontaneous tension pneumocephalus resulting from a scalp fistula in a patient with a remotely placed ventriculoperitoneal shunt. Ann Emerg Med 56:378-381, 2010

34. Morishita A, Nagashima T, Kurata H, Eguchi T, Tamaki N: [Clinical analysis of pediatric shunt catheter fracture.] No Shinkei Geka 30:839-845, 2002 (Jpn)

35. Nulsen FE, Spitz EB: Treatment of hydrocephalus by direct shunt from ventricle to jugular vain. Surg Forum 1951:399403, 1951

36. Ogiwara H, Dipatri AJ Jr, Alden TD, Bowman RM, Tomita T: Endoscopic third ventriculostomy for obstructive hydrocephalus in children younger than 6 months of age. Childs Nerv Syst 26:343-347, 2010

37. Park MK, Kim M, Park KS, Park SH, Hwang JH, Hwang SK: A retrospective analysis of ventriculoperitoneal shunt revision cases of a single institute. J Korean Neurosurg Soc $\mathbf{5 7 : 3 5 9 - 3 6 3 , 2 0 1 5}$

38. Ramsey DB, Chadduck WM: Premature fractures of platinum-cured Silastic shunts. Childs Nerv Syst 8:406-410, 1992

39. Reddy GK, Bollam P, Caldito G: Long-term outcomes of ventriculoperitoneal shunt surgery in patients with hydrocephalus. World Neurosurg 81:404-410, 2014 
40. Sainte-Rose C, Piatt JH, Renier D, Pierre-Kahn A, Hirsch JF, Hoffman HJ, et al: Mechanical complications in shunts. Pediatr Neurosurg 17:2-9, 1991-1992

41. Salim AD, Elzain MA, Mohamed HA, Ibrahim Zayan BE: Shunt tube calcification as a late complication of ventriculoperitoneal shunting. Asian J Neurosurg 10:246-249, 2015

42. Shah SS, Hall M, Slonim AD, Hornig GW, Berry JG, Sharma V: A multicenter study of factors influencing cerebrospinal fluid shunt survival in infants and children. Neurosurgery 62:1095-1103, 2008

43. Shannon CN, Acakpo-Satchivi L, Kirby RS, Franklin FA, Wellons JC: Ventriculoperitoneal shunt failure: an institutional review of 2-year survival rates. Childs Nerv Syst 28:2093-2099, 2012

44. Singh G, Kaif M, Ojha BK, Chandra A, Cronk K, Nakaji P: Torticollis as a late complication of ventriculoperitoneal shunt surgery. J Clin Neurosci 18:865-866, 2011

45. Stannard MW, Rollins NK: Subcutaneous catheter calcification in ventriculoperitoneal shunts. AJNR Am J Neuroradiol 16:1276-1278, 1995

46. Stone JJ, Walker CT, Jacobson M, Phillips V, Silberstein HJ: Revision rate of pediatric ventriculoperitoneal shunts after 15 years. J Neurosurg Pediatr 11:15-19, 2013

47. Tamber MS, Klimo P Jr, Mazzola CA, Flannery AM: Pediatric hydrocephalus: systematic literature review and evidencebased guidelines. Part 8: Management of cerebrospinal fluid shunt infection. J Neurosurg Pediatr 14 (Suppl 1):60-71, 2014

48. Vernet O, Rilliet B: Late complications of ventriculoatrial or ventriculoperitoneal shunts. Lancet 358:1569-1570, 2001
49. Wu Y, Green NL, Wrensch MR, Zhao S, Gupta N: Ventriculoperitoneal shunt complications in California: 1990 to 2000. Neurosurgery 61:557-563, 2007

50. Yamamoto S, Ohno K, Aoyagi M, Ichinose S, Hirakawa K: Calcific deposits on degraded shunt catheters: long-term follow-up of V-P shunts and late complications in three cases. Childs Nerv Syst 18:19-25, 2002

\section{Disclosures}

The authors report no conflict of interest concerning the materials or methods used in this study or the findings specified in this paper.

\section{Author Contributions}

Conception and design: Lee, S Low, D Low. Acquisition of data: Lee, S Low, Ng, Nolan, Seow. Analysis and interpretation of data: Lee, S Low, Ng. Drafting the article: Lee, S Low. Critically revising the article: S Low, D Low, Seow. Reviewed submitted version of manuscript: S Low, D Low, Nolan, Seow. Statistical analysis: Lee. Administrative/technical/material support: S Low. Study supervision: Seow.

\section{Correspondence}

Lester Lee, Neurosurgical Service, KKH Women's and Children's Hospital (Singapore), 100 Bukit Timah Rd., Singapore S308433, Singapore.email: lester.lee@doctors.org.uk. 